\title{
A Queer Journey: Mahabharata to Ghosh's Chitrangada
}

\section{Sheenjini Ghosh}

\author{
"Within infinite myths lies an eternal truth \\ Who knows it all? \\ Varuna has but a thousand eyes \\ Indra, a hundred
}

You and I, only two."(Chitrangada: The Crowning Wish.) From time immemorial, queer sexuality has formed an integral part of the Hindu mythological folklore. However, its interpretation have always been smudgy and vague as these stories, symbols, and rituals have suffered from explanations devoid of adequate enquiry, profound interrogation and wide vision. Therefore, there has remained a chiasmic difference between the queer ideas celebrated in these stories and their shallow interpretations in our Indian society due to the ignorance and rigidity prevalent in it.

Devdutt Pattanaik, a mythologist, and an illustrator has made a compilation of such stories and has compared them to the Greek lore, and The Bible to show how "different cultures express and repress sexuality in different ways in different times." He states that while in the Hindu lore, the god, himself, would "become women" to tempt hermits or to trick demons, there is no such taleof change of sex or same sex love in The Bible (for it amounted to blasphemy).Pattanaik had explained that in the Hindu worldview nothing can be taken as permanent in the entire cosmos-

"As one oscillates between the land of the dead and the land of the living, genders change, orientations change, identities change-the future being determined by the past. Masculinity and femininity are reduced to ephemeral robes of body and mind that ensheath the sexless, genderless soul. The ultimate aim in the journey of life then becomes an exercise in appreciating the beauty of existence, understanding its limitations, before finally transcending it."

In this paper, my attempt will be to trace one such queer journey that is rooted in the Indian tradition, right from The Mahabharata to the 21st century film of Rituparno Ghosh. While tracing this journey, I will refer to the tale of Mahabharata, the dualism or the androgyny rooted in
Vaishnavism and explore Tagore's interpretation of Chitrangada before proceeding to Rituparno Ghosh's film Chitrangada: The Crowning Wish.

Myriads of instances can be found in the celebrated epic, The Mahabharata, through the 'queer' characters like Brihanalla, the eunuch form of Arjuna to Shikandi, the form after queer rebirth of Amba and so on. It can be observed in case of Chitrangada, the princes of Manipur, who was raised like a man; in case of Mohini, whom Vishnu had cross-dressed to trick the demons. Again, in the VaishnavaSakhi- sect, the monks take up female apparel to be the Sakhis of Radha to be close to Krishna. Chaitanya has been regarded as the epitome of cultural androgyny of this country (Bakshi). In Rituparno Ghosh's words, "Radha and Krishna are almost symbiotic in him." But, although, the Hindu Philosophy provides room for cross dressing and queer personalities, these instances were 'tolerated' within safe parameters of the 'divine'. Socially, people were expected to "follow a parampara or belong to a sampradaya with rules and codes of conduct fixed either by caste or by the guru." Pattanayak has argued that, according to the Dharmashastras, the ancient Hindu law book, heterosexual marriages and bearing of children are the most important duties of a person. Manusmriti(500 B.C.), another law book, condemned same sex activities and also prescribed punishments for the same. The idea of 'queer' in India represented a colonial category, an instrument to stigmatize subjects, who were sexual deviants and gender outlaws, and to demark as cultural aberrations, which 'can' not or even, 'should' not be assimilated into the sphere and machinery of normative colonial thought.

Here is an excerpt to show how The Bhagvad Gita talks of "Prakriti" and "Purusha".

"It talks of 'Purusha' as the soul, the Self, pure consciousness, and the only source of consciousness. The word literally means "man". 'Prakriti' is something that is created. It is nature in all her aspects. 'Prakriti' means "creatrix," the female 
creative energy. The 'Purusha' is the universal cosmic male, the supreme Brahman, the subject as well as the object of sacrificial ceremonies, whose selfsacrifice results in the manifestation of life and worlds and by making a sacrifice to whom, a person gains an entry into the higher worlds or achieves liberation itself. The 'Samakhya' philosophy states that 'purusha' did not create 'prakriti'; in fact, if given a choice, 'purusha' would prefer to have never met 'prakriti' at all. It, further, states how being the purest reflection of Sri Krishna himself, Radha is 'Prakriti' the feminine, while Sri Krishna is 'Purush' the masculine. They are blended together, intricately intertwined in such a way that either both exist or none."

Chitrangada, in The Mahabharata, scripted by VedVyasa, is the story of a princess, who is one of Arjuna's wives. During his exile for twelve years, Arjuna, still practicing Brahmacharya, visits Manipur. Enamored by the princess, Chitrangada, there, he expresses the wish to marry her. But, Chitrangada's father, the king of Manipur, initially refuses the proposal for in a matrilineal society such as theirs, a child born of Chitrangada would become the future ruler. Arjuna marries her on the condition that Chitrangada would not accompany him on his way back to his kingdom and that he would have no claim upon the child born. The son who was born to Chitrangada and Arjuna, Babruvahana succeeded his grandfather as the king of Manipur and later unknowingly defeats his own father Arjuna in battle.

But, Chitrangada, in The Mahabharata is just taken to be (but not even treated like) a son by Chitravahana. She is attributed as "charudarshana" and "bararoha"- good looking and curvaceous, i.e. well- proportioned, in particular with beautiful waist and hips. The King clearly puts it, that it is his "bhavana" i.e. fancy, that she is his "putra."The Mahabharata has enjoyed a widely favorable reception for its exploration of the identity of Chitrangada has been visibly confined within the heteronormative boundaries.

Dr. SudeshnaMitra in one of her papers titled "The Travels of Chitrangada and Tagore's Philosophy"points out the difference in Tagore's representation quite aptly.She states that, "Rabindranath Tagore gave this ancient tale an amazon twist, perhaps influenced by folk narratives based on The Mahabharata. In his opera, Chitrangada's father wants a son but, instead, is 'cursed' with a daughter by the gods. He raises this daughter as a man, a warrior. During a hunt she captures the handsome Arjun, who is on a twelve-year exile from his own land. She falls in love with him but fears Arjun may reject her because of her 'manly' preferences. (In fact, he assumes she is a 'man' because she is such a good warrior). Driven by her desire, Chitrangada asks 'Madan', god of love, to make her more womanly. She approaches Arjun thus, and Arjun falls for her. When Manipur is attacked, people cry out for the warrior-princess and Arjun learns of her for the first time. He longs to meet this woman who he feels is extra-ordinary. A pleasantly surprised, Chitrangada, begs Madan to restore her to her original form. Arjun loves her even more. Thus, Arjun loves Chitrangada for who she is, rather than for what she has become. "

Within the radical re-casting of the tropes, however, in all his versions, Tagore portrays the original and metamorphosed Chitrangada most stereotypically. She is first 'manly' and, therefore, Kurupa (or ugly). She is groomed as a "man", a warrior in his family and society. She is also presented as someone failing to court Arjuna because of her manly features, even when she puts on women's garb. In fact, when she later recounts her encounter with Arjuna, she describes herself as having behaved shamelessly "as though she were a man (Chitra 56-5); for a woman with lajja, a 'bhadramahila', would not make the first overture to a man. Chitrangada is further represented in terms of the then existing stereotype of a beautiful woman when she is metamorphosed by Madana into a "Feminine" and therefore exquisitely beautifulwoman. Tagore's emphasis on the masculine- feminine binary brings about an underlying suggestion of some sort of androgyny as an ideal. Towards the end, Tagore'sChitrangadaproclaims,

"I am Chitrangada, the precious daughter of the King of Manipur,

Neither a goddess, nor a woman, commonplace and mundane.

Allowing me to be a true partner in your life's journey

I am not the one you hail in the altar, worshiping,

Nor am I the one you keep behind you, in negligence.

Once you recognize my essence, keeping me beside you

Amid your deep hours of crisis,

Allowing me to be a true partner in your life's journey,

A true accomplice in your missions, 
Only then you will know my true self." (Banerjee)

In the first, the stereotype of the woman as 'abala' (bereft of strength) or the weaker sex appears again and again. "I know no feminine wiles for winning hearts. My hands are strong to bend the bow..."(Tagore1914:3) After being ignored by Arjuna, she renounces her "man's clothing ... the unaccustomed dress clung about my shrinking shame ..." Tagore's attempt continues to be the valorization of the inner, essential self over the relatively insignificant outer form.

"Alas, I have failed the woman in me / thus far in my life/ shame to the bow and arrow/ shame to my strong arms".

Even in case of Tagore, although there is slight consolidation from that in The Mahabharata, not much liberation of identity or gender is achieved. However, Ghoshmakes a significant departure from the common discourse of Chitrangada.

Just as Tagore was poised in the cusp of modernity, Ghosh's context is that of the globalized, postmodern epistemic moment. His way of contemporizing it with a sharp dose of intertextuality sees a queer twist in the tale he receives from his idol, Tagore. The film Chitrangada: The Crowning Wish depicts the dance drama within the cinema. While rehearsing the opening scene(within the frame narrative), where Chitrangada and her friends are shown capturing Arjuna, the bare chested actor playing Arjuna is revealed as a young man with long hair and a six-pack body and the actor playing the role of Chitrangada ( Kasturi) as the "manly" princess. Rudra's deep attachment with the character of Tagore's heroine makes him upset with the actor playing Chitrangada, for she acts too dainty to be mistaken for a man, both by Arjuna and the spectators. Rudra goes on to explain Tagore's purpose by saying that Chitrangada was conditioned to be a man by her father and so her body language needed to be shown to be that of a man." It was only when she saw Arjuna that she wished to be a woman." For Ghosh, this is the queer moment that he sets out to unpack in this film.

Ghosh exploits the concept of Jatracuture that necessitates a transformation resulting in a liberation of the physical, intellectual and emotional 'self' to 'become' who or what one plays. Sunil Pant, the founder of the Blue Diamond Society, a Nepalese LGBTIQ organization accentuates the necessity of preserving a separate feminine identity in an otherwise world of over-hyped Western masculinity. Women empowerment is about 'to be' rather than 'to become'. Pant states that, "It is here that these feminized festivals teach the value of beauty, fluidity, gentleness, flexibility, diversity and compassion instead of naively participating in the 'culture of transformation' that cages the individual's mind and body into pre-defined machismo, rigidity, standardization, brutality, hatred and beauty and glamour phobias. "

For us, this is the queer spectatorialphantasma that Ghosh/ Rudra's queer subjectivity gazes and seizes upon. "Rituparno portrays Chitrangada as a story of desires and self-realisation, evoking many thoughts and questions which are gender and identity related. In the introduction to the cinema, as a director he writes- "from Tagore's writings comes a realization". In the film there are two dimensions, two tales are being told intertwined with each other: the story of Chitrangada and story of the protagonist of this film, Rudra." (Mitra) In the beginning of the film, a heavily drugged Rudra halfway through his gender correction surgery, is seen telling the plan to Subho of how he wishes to stage Chitrangada, a product of his hallucinated imagination. He reads out the introduction of his script, "It had to be an heir - that was all the father knew, to carry on the name and the family pride and so the training began, but the child to be a girl or a boydid anyone ask or even want to know -children have dreams beyond their parents' expectation and they wish on stars and fallen eyelashes. Sometimes wishes come true, unexpectedly to crown a life and turn the everyday inside out." However, unlike Chitrangada, Rudra is born male. Unlike Chitrangada who is raised as a woman and assumes manly features, Rudra's parents want him to go for counselling to cure his effeminacy and save them from social embarrassment. Though what followed after Chitrangada underwent a metamorphosis from "Kurupa" to "Surupa", is unclearwhether she was banished from the court by her father as he could not accept her new refined identity or was it the royal proclamation that spread the rumor of her going on a pilgrimage. However, people around Rudra fail to feel his pulse throughout the movie. Rudra is forced to feel that he is a "perennial embarrassment to his parents", his well-wishers including his parents and Mala,an ex-dancer of Rudra's troop harbor the thought that whoever wins Rudra's affection wins it only to take advantage of the latter.Rudra, however, defends his choice of his willingness to "suffer Partho" as he believes that though many "appreciates his worth", it is rare to find one who has the "guts to love him"- he believes Partho has it. Moreover, Partho's heroine addiction reflects images of his own ostracization within the heteronormative regime. Rudra believes that "it is not important, how we lead our lives but how we wish to lead it" and thus on being questioned by his father why he had to study engineering 
when all he wanted was to tie the ghungroo round his feet and enact Madan on stage, his curt reply was that he was coerced into studying it. Rudra is evidently suffering from a constant conflict between his own thought and the thought of others. His father hates the idea of him being associated with a feminine profession, Rudra believes that he is fortunate enough to be professionally associated with such an art form which is not gender-bound. With time, Rudra gets to learn of Partho's affection towards children. He warns Partho to give their relationship a second thought and move out if needed. Partho insists that they might even adopt a child if it's necessary for them to stay together. On learning about the Indian law that prohibits two adult male parents from adopting a child, Partho clearly states that he is determined to do without one for the rest of his life. Rudra decides to take a serious plunge for securing his relationship with Partho and ensuring the latter's happiness. When Rudra expresses his desire for a Sex Reassignment Surgery, Partho considers it to be a mad man's decision and warns him that this unnecessary tampering of his body- the "main instrument" of his profession might cost him a lot. He vehemently criticizes Rudra for thinking of such an option and asks him to accept the fact that he is not happy with his "natural self". Rudraretorts back that nobody is happy with their natural self, otherwise none of the men would have hit the gym to transform their body and none of the women would have visited the parlour. Partho becomes disgusted at such lame comparisons and states that the transformation Rudra is opting for has severe side effects and that he loves him just the way he is. Rudra's counter question whether he will be loved less if he becomes a woman goes unanswered. The fact that Rudra dances not from his body but from within and that his identity is not gender bound just like his profession is not, is beyond the grasping capacity of all and sundry. In the climax of the play,Chitrangada pleads with Arjun to ignore the bodily beauty and accept her for her essential, true self as the spell of Madana for one year comes to an end, Rudra similarly undergoes bodily transformation at the hands of the plastic surgeon in order not to become more beautiful but "technically a woman" so that he and Partho could adopt a child, despite the disapproval of Partho to this decision. In contrast to Chitrangada, the change leaves a deep traumatic impact, as if to bring out the lack of psychological depth and psychological realism in the portrayal of Chitrangadafrom being coerced into imagining herself as a man first and then realizing the reality of her female desire. Thus, though within the film, Rudra's theatrical interpretation is lauded by the press, he is himself deeply dissatisfied with his handling of the theme. He is able to realize this only through his personal situation in relation to his homophobic father, the culture in which he lives and finally through Partho saying , “ If I am to marry a real woman, why marry this synthetic half way thing?" It is at this juncture that Rudra is confronted with Subho's question," How do you want to be remembered? As an artist or as Surupa?" It is at that moment, Rudra realizes that he doesn't need to get into the heteronormative box approved by the society, he doesn't need to have a woman's body to realize his feminine desires and get the authentication of the society.

In an interview Ghosh had once retorted, "Our understanding of sexuality is sadly limited by the binary heterosexuality/homosexuality. There are several sexual identities which none of [the terms prevalent nowadays] can possibly contain or define. ....In any case, our identities are subject to the body which again is a boundary....I believe in transcending that boundary... the body is in a state of transition...perennially...so, is my identity. Therefore, it is not desirable to identify with a single category."

It is in fact impossible. Everything is in a state of making...eternally...nothing is ever complete...the same is true of the body and therefore, identity. It's a continuous process." Rudra thus realizes that "The body is not about physical boundaries, it is about the relationship between him and the person perceiving it."(Chitrangada: The Crowning Wish.)Rudra, thus, gives up his desperate attempt to become "technically" a woman, and thereby decides to return to his original state. As we approach the end of the celluloid, we see that Rudra instead of being united to Partho, is united to his family. But, this unity is somewhere made possible by Rudra's realization of his failure of being accepted and understood. In one scene, Rudra's mother had confessed, "It is easy to blame him alone, we are also to be blamed. We knew it all along but we wouldn't accept. We insisted just because he's born a boy, he should be like a boy."Rudra's father's reply seems to loom omnipresent, "What's there to insist? Boys should be Boys, That's Natural."

Rudra shows his breast implantations to Partho but soon comes to know about Partho's disgust at it. His decision for the implantation is driven by his desire to please Partho, but it soon suffers a tragic setback. Rudra further learns that Partho is seeing Kasturi and that they are planning to get married. Rudra once again suffers disappointment - a disappointment that makes him demand for whom he has endured all the pain but received, in return, a retort from Partho that he never wanted him to change. Partho further claims that he has gone through a lot to change his past and 
that cigarettes are his only addiction. He has come out clean from heroine addiction. He mocks Ruddie for his martyrdom, for helping Partho normalize. At this point, Ghosh underscores the sentiments of the moment with an apt background song - "Withashes, the tiring flames you cover. What game is this, you are playing, Oh, Lord of Desire ! How much longer? "The encounter is wrecking for Rudra. He ends questioninghis understanding about the world and his own 'self'. He even discusses with Subho about the prospects of aborting the planned surgery.

At this point, Partho returns to Rudra with the news that Kasturi is expecting but that she is determined to abort the child. Ironically, Rudra who wanted to make provisions to ensure the same but did not get the support, suddenly finds Partho lending the same to Kasturi who does not want to destroy her career by starting a family and bearing a child. Rudra's parents visit him at the hospital and asks whether he wants to change his name, to suit his change of identity. With that will come the necessityto make an affidavit to modify what was previously written in their will "My son, the only heir."Rudra replies his father if it suits him, he can introduce him as his son. Unlike his parents, Rudra sees a meaninglessness in every act, an impermanence in everything including the meaning of the word 'heir'. He wonders what that word could refer to - the son they gave birth to or the 'strange creature' that is returning to their house that day. The parents, and the world at large can "neither handle [him] nor ignore [him]". (Ghosh interview).

Ghosh includes a scene where Rudra and Subho reflects on Rudra's implantation and new identity.Rudra asks Subho what if dies on the operation table. Subho aptly observes that even if he does not die, it is death itself, for from the table will emerge a new person with a new life and new identity. As it is unfeasible to lead two lives together, he will have to choose one. In that case, Rudra says he prefers to be remembered as the vivacious, energetic, eccentric creative dancer and not as the transformed Chitrangada, a form that is both impermanent and mortal.

The final scene shows Rudra on the OT bed awaiting the beginning of surgical procedure to remove his breast implants. When the doctor urges Rudra to given them a phone number he remembers, he incidentally mentions that of Partho. However, when the doctor calls Partho, the latter says Rudra can be what he wishes to be and that it is no more than his own wish. And, the film ends, with an equally apt song "Give me new life, O lord of Life, This Blessed Morning, Banish all ills in this new rejoicing,destroy the traces of night in new dawning."
The film is shocking to many to such an extent that it estranges Ghosh to his own audience. Ghosh states that "I am aware of the loss. A lot of them are wary of my crossdressing in public! In fact, the respect I used to command has been seriously affected by my decision to proclaim my sexuality."

He also states, "I was aware that I would end up alienating a section of my audience which had never associated my sexual preference with my work. Even then, I could not be mendacious about my sexuality. That would have been dishonest. "Understandably the film estranges a section of heteronormative audience who believes in the sole existence of the 'binary' and to some extent, those who have enduredthe Sex Reassignment Surgery.

But the film leaves some unavoidable questions before the audience. The perspective in the film Chitrangada and Ghosh himself have often been targeted as products of Occidental hedonism and thereby seen as alienated from the Orient. It is quite disturbing to think why the versions of Mahabharata and Tagore won a reception of repute while Ghosh's suffered from vehement criticism. Is it because he overcomes the rigidity of the binary and presents the tale of one who is different from it? Is it because the audience/spectators are too naively driven towards judging his actions instead of empathizing with his emotions? Or is it because we his wishes or desires are unrecognized hence, the 'crowning wish' satisfactorily unfulfilled.

It is to be remembered that Ghosh has made this film much before the legality of 377 has been approved. But, the act of legalizing 377 has not reduced the struggle and misery of the 'queer'. For it is a seemingly indelible popular impression that such 'queer' people and their equally 'queer' desires cannot, should not, and must not exist. And their own 'queer' desire overrides the natural desires of the 'queer'. A popular radio jockey, later turned anchor and actor was often seenmimicking the gesture of Ghosh on public platform, subjecting the latter to almost scorn and ridicule for popularity. Ghosh later had to intervene and bring it to the consciousness of the mentioned person that in gaining popularity he is hurting the sentiments of a particular section who idolizes Ghosh. Ghosh stated that simply by mimicking certain gestures, does not make the latter emulate the true self of Ghosh as Ghosh is way beyond his reach. Ghosh works on this liberation of the political, cultural and sexual self and identity and reinstated the need of constantly working on it. Ghosh echoes Butler's notion of Gender Performativity and challenges the shaming of men who indulge in dance by dissociating gender from performance arts. It is the 
participation in these performing arts that is shown to have vaulted possibilities of new identities and liberated the deepseated gender-based notions with respect to performing arts which is not only important, but also necessary.

Thus, Ghosh transcends stereotypical cultural spaces to open up possibilities of articulation of their desires and identities by the minorities. But, it remains a matter of debate and concern whether it will be heard and given due attention, whether it will be able to break through the strongly rooted stereotypical heteronormative boundaries as envisaged.

\section{REFERENCES}

[1] Bakshi, Kaustav. "Interview of Rituparno Ghosh by KaustavBakshi-'I Know My City Can Neither Handle Me nor Ignore Me'." Academia.edu - Share Research, Silhouette: A Discourse on Cinema (Vol 10, No. 3), May 2013, www.academia.edu/3501746/Interview_of_Rituparno_Ghosh by_Kaustav_Bakshi-

I_know_my_city_can_neither_handle_me_nor_ignore_me.

[2] Bakshi, Kaustav. "Rituparno Ghosh, Performance Arts and a Queer Legacy: an Abiding Stardom.” Academia.edu - Share Research, Taylor and Francis, 28 Mar. 2017, www.academia.edu/32404061/Rituparno Ghosh performanc e_arts_and_a_queer_legacy_an_abiding_stardom.

[3] Bakshi, Kaustav\&Sen, Parjanya. (2015). A Room of Hir Own: The queer aesthetics of Rituparno Ghosh.

[4] Banerjee, Lopa. "Rabindranath Tagore's Chitrangada: English Translation (Part I)." Learning and Creativity, L\&C Silhouette Newsletter, 14 Feb. 2018, learningandcreativity.com/rabindranath-tagore-chitrangadaenglish-translation-part-i/.

[5] Butler, J. (1993). Bodies that Matter. New York: Routledge.

[6] Butler, J. (1999). Gender Trouble. New York: Routledge.

[7] Dasgupta, Rohit K. "Opening Closets and Dividing Audiences: Rituparno Ghosh, the Queer Star of Bengali Cinema." Academia.edu - Share Research, South Asian Popular Culture, 2018, www.academia.edu/36310422/Opening_closets_and_dividing _audiences_Rituparno_Ghosh_the_queer_star_of_Bengali_ci nema.

[8] Dasgupta, Rohit K. "Rituparno Ghosh: Cinema, Gender and Art." Academia.edu - Share Research, Routledge, Dec. 2015, www.academia.edu/14108303/Rituparno_Ghosh_Cinema_Ge nder_and_Art.

[9] Datta, Sangeeta\&Bakshi, Kaustav\&Dasgupta, Rohit. (2015). The world of Rituparno Ghosh: Texts, contexts and transgressions. South Asian History and Culture. 6. 1-15. 10.1080/19472498.2014.999441.

[10] Ghosh, Rituparno (2012) directed, Chitrangada: The Crowning Wish, Shree Venkatesh films.

[11] Interview Series, "ChitteyChitrangada", Sangeet Bangla, 10 September, 2012. http://youtu.be/71Xx_690cW4
[12] Mitra, Dr. Sudeshna. Heritage : The Travels of Chitrangada and Tagore's Philosophy. www.bethunecollege.ac.in/heritagejournal/journals/heritageJo urnalVolII2015/articles2015/TheTravels-of-Chitrangada-andTagore-PhilosophyHeritage2015.pdf.

[13] Mukhopadhyay, Shalini. "The 'Other' in Performing Arts." Academia.edu - Share Research, www.academia.edu/38076269/The_other_in_performing_arts.

[14] Pant, Sunil. "It Is a Cosmic Dance, Not Cross-Dressing! Understanding the Culture and Festivals of Nepal." Gaylaxy Magazine, $24 \quad$ July 2017, www.gaylaxymag.com/articles/world/cosmic-dance-notcross-dressing-understanding-culture-festivalsnepal/\#gs.Z1Akbq5I.

[15] Pattanaik, Devdutt. Shikhandi and Other Tales They Don't Tell You. Zubaan and Penguin Books India, 2014.

[16] Pattanayak, Devdutt, (2002), The Man Who Was a Women and Other Queer Tales from Hindu

[17] Lore, Harrington Park Press.

[18] Pattanaik, Devdutt. The Transformations of Chitrangada. Devlok, 31 July 2013, devdutt.com/articles/indianmythology/the-transformations-of-chitrangada.html.

[19] Rajagopalachari, C. Mahabharata. BharatiyaVidyaBhavan, 2002.

[20] Satpathy, Sumanyu. “'As Though She Were a Man': Chitrangada and Contemporary Queer Appropriations of Tagore." SpringerLink, Springer, 1 Jan. 1970, link.springer.com/chapter/10.1007\%2F978-81-322-20381 13.

[21] Sen, Parjanya. "De-Gendered Expressions: the 'Chitrangadas' of Tagore and Ghosh." Academia.edu - Share Research, www.academia.edu/2612092/De-

Gendered_Expressions_the_Chitrangadas_of_Tagore_and_Gh osh. 